Int. J. Electrochem. Sci., 13 (2018) $2817-2828$

\title{
Sediment Microbial Fuel Cell with Double-Anode Arrangement for Enhanced Oxygen Reduction Reaction
}

\author{
Qinzheng Yang ${ }^{1, *}$, Dexue Luo ${ }^{1}$,Jing Yang ${ }^{2}$, Wenrui Shen ${ }^{1}$, Xin Liu ${ }^{1}$, Xiaoran Zhao ${ }^{1}$ \\ ${ }^{1}$ Department of Bioengineering, Qilu University of Technology (Shandong Academy of Sciences), \\ Shandong Provincial Key Laboratory of Microbial Engineering, Jinan250353, P.R. China. \\ ${ }^{2}$ Department of Sciences, Qilu University of Technology (Shandong Academy of Sciences), Jinan \\ 250353, P.R. China. \\ *E-mail: yqz@qlu.edu.cn
}

doi: $10.20964 / 2018.03 .19$

Received: 30 November 2017 / Accepted: 27 December 2017 / Published: 5 February 2018

\begin{abstract}
Biofilms formed on the cathodes of sediment microbial fuel cells (SMFCs) are mainly composed of heterotrophic bacteria that inevitably attach to cathode catalytic sites, inhibit the oxygen reduction reaction (ORR), and affect the practical performances of SMFCs. In the present work, a novel doubleanode sediment microbial fuel cell (DA-SMFC) was designed and constructed with a commercial nitric acid-activated carbon felt set at sediment-water interface, and its electrical power generation performance and antibacterial mechanism were investigated. The voltage generation capacity of DASMFC reached up to $376 \mathrm{mV}$, higher than those of the sediment microbial fuel cell (SMFC) (332 mV) with the carbon felt put in sediment, due to the higher total organic carbon (TOC) removal efficiency. The electrochemical impedance spectroscopy, bacterium protein content, and SEM analyses indicated that the formation of biofilm on the cathode of DA-SMFC was significantly inhibited, resulting in significantly reduced protein contents on cathode, and decreased $\mathrm{R}_{\mathrm{ct}}$ from $118.9 \Omega$ to $91.6 \Omega$. This novel DA-SMFC system exhibited excellent antibacterial performances by inhibiting the migration of organic matters from the sediments to the cathode in overlying water, which would promote the application of SMFC.
\end{abstract}

Keywords: Sediment microbial fuel cell, Double-Anode, Oxygen reduction reaction, Biofilm, Electricity generation

\section{FULL TEXT}

(C) 2018 The Authors. Published by ESG (www.electrochemsci.org). This article is an open access article distributed under the terms and conditions of the Creative Commons Attribution license (http://creativecommons.org/licenses/by/4.0/). 